\section{Commentary: Data zenith}

\author{
Matheus P. Falasa, MD, and \\ Thomas M. Beaver, MD, MPH
}

The article "Long-term outcomes of aortic root operations in the United States among Medicare beneficiaries" in this issue of the Journal, ${ }^{1}$ written by esteemed aortic surgeons Yerokun and colleagues, represents the culmination of countless hours of work by numerous surgeons dedicated to quality improvement. ${ }^{2,3}$ Linking data from the Society of Thoracic Surgeons and Medicare databases, the authors analyze real-world contemporary outcomes in 4173 patients out to 7 years, finally allowing for meaningful conclusions about the downstream effects of our surgical interventions on the aortic root. Three observations can be made about current root procedures.

First, the long-term outcomes from mechanical valve modified Bentall procedures showed surprisingly higher than expected rates of both stroke $(12.9 \%)$ and bleeding $(20 \%)$ at 7 years, ${ }^{1}$ making alternative procedures more attractive in the Medicare population. Importantly, the risk-adjusted mortality at 7 years was higher in the mechanical valve group compared with the biologic valve groups in this elderly population.

Second, the authors demonstrate that surgeons have already begun to use more stented bioprosthetic valves as part of modified "bio-Bentall" procedures (increasing from $17 \%$ of cases in 2004 to $35 \%$ of cases in 2013), presumably in anticipation of future transcatheter aortic valve replacement (TAVR). Bioprosthetic valve failure rates, cited at $7 \%$ at 6 years, pose less of a concern in the era of TAVR, ${ }^{4}$ with stented valves having technical advantages for later TAVR over stentless valves, which lack radiopaque markers.

\footnotetext{
From the Division of Cardiovascular Surgery, Department of Surgery, University of Florida, Gainesville, Fla.

Disclosures: The authors reported no conflicts of interest.

The Journal policy requires editors and reviewers to disclose conflicts of interest and to decline handling or reviewing manuscripts for which they may have a conflict of interest. The editors and reviewers of this article have no conflicts of interest.

Received for publication March 3, 2021; revisions received March 3, 2021; accepted for publication March 4, 2021; available ahead of print March 9, 2021.

Address for reprints: Thomas M. Beaver, MD, MPH, Division of Cardiovascular Surgery, Department of Surgery, University of Florida, 1600 SW Archer Rd, Gainesville, FL 32610 (E-mail: thomas.beaver@surgery.ufl.edu).

J Thorac Cardiovasc Surg 2023;165:566-7

$0022-5223 / \$ 36.00$

Copyright (c) 2021 by The American Association for Thoracic Surgery

https://doi.org/10.1016/j.jtcvs.2021.03.012
}

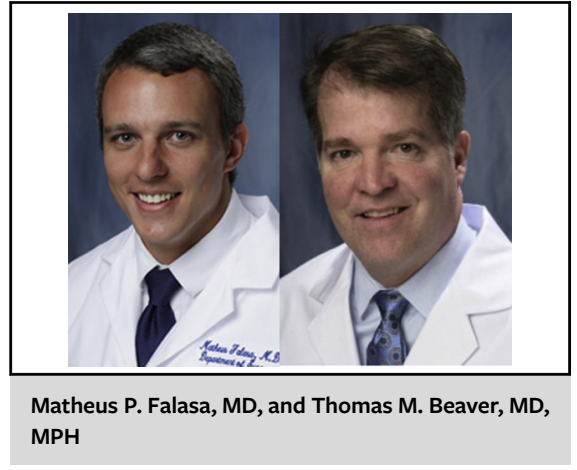

CENTRAL MESSAGE

Combining Society of Thoracic Surgeons and Medicare databases demonstrates long-term advantages of and preference for the stented Bio-Bentall. More reproducible aortic valve sparing techniques may offer further benefits.

Finally, the article provides additional important information about "valve-sparing" root procedures, which remain the preferred choice at major aortic centers (including a non-statistically significant survival benefit and a statistically significant reduction in stroke rate cited by the authors). ${ }^{1}$ However, when valve-sparing operations are performed at multiple centers, there is a notable failure rate $3 \%$ requiring valve reintervention at 7 years in this study). ${ }^{1}$ The success of these operations currently depends on the intraoperative assessment and technical expertise of experienced surgeons. Schäfers has highlighted the importance of standardizing the analysis and repair techniques to maintain reproducibility between surgeons and centers. ${ }^{5}$ Our center has adopted the "Florida sleeve" procedure, which is less technically complex than other aortic valve-sparing techniques, can be expected to have higher reproducibility, and has $98 \%$ freedom from reoperation out to 8 years. ${ }^{6}$

In summary, we are indebted to the work of Yerokun and colleagues and the other many Society of Thoracic Surgeons database champions, ${ }^{2,3}$ who with their foresight to combine forces with the Medicare database have achieved a "data zenith," providing critical data and feedback about longitudinal outcomes that will enable us to refine the 
choices of operative procedures for patients moving forward.

\section{References}

1. Yerokun BA, Vallabhajosyula P, Vekstein AM, Grau-Sepulveda MV, Benrashid E, Xian Y, et al. Long-term outcomes of aortic root operations in the United States among Medicare beneficiaries. J Thorac Cardiovasc Surg. 2023;165:554-65.e6.

2. Jacobs JP, Edwards FH, Shahian DM, Haan CK, Puskas JD, Morales DLS, et al. Successful linking of the Society of Thoracic Surgeons adult cardiac surgery database to Centers for Medicare and Medicaid Services Medicare data. Ann Thorac Surg. 2010;90:1150-6; discussion 1156-7.
3. Jacobs JP, Shahian DM, He X, O'Brien SM, Badhwar V, Cleveland JC Jr et al. Penetration, completeness, and representativeness of the Society of Thoracic Surgeons Adult Cardiac Surgery Database. Ann Thorac Surg. 2016;101:33-41.

4. Søndergaard L, Ihlemann N, Capodanno D, Jørgensen TH, Nissen H, Kjeldsen BJ et al. Durability of transcatheter and surgical bioprosthetic aortic valves in patients at lower surgical risk. J Am Coll Cardiol. 2019;73:546-53.

5. Schäfers HJ. Commentary: Thirty years of valve preserving surgery-are all questions answered? J Thorac Cardiovasc Surg. 2021;161:903-4.

6. Aalaei-Andabili SH, Martin TD, Hess PJ, Karimi A, Bavry AA, Arnaoutakis GJ et al. The Florida Sleeve procedure is durable and improves aortic valve function. Aorta (Stamford). 2019;7:49-55.
See Article page 554

\section{Commentary: The root of the matter}

Dawn S. Hui, MD, and Andrea J. Carpenter, MD

In this edition of the Journal, Yerokun and colleagues ${ }^{1}$ use the power of linking Medicare claims data with the Society of Thoracic Surgeons database to provide insight into longterm outcomes of aortic root replacement (ARR) in Medicare beneficiaries. From 2004 to 2014, notable trends included more than a doubling in the use of stented bioprosthetic Bentall with decreasing use of mechanical Bentall, stentless Bentall, and valve-sparing root replacement (VSRR). These trends likely have been driven by the potential of valve-in-valve $(\mathrm{ViV})$ transcatheter aortic valve replacement (TAVR) as a treatment for valve degeneration. As the authors discuss, modes of failure vary among the ARR options, and although a bioprosthetic Bentall has perhaps the most certainty for degeneration, it also poses the least technical difficulties for transcatheter therapy.

Another potential contributing factor is our field's continuous commitment to improving long-term outcomes. Here perhaps the impact of previous studies on practice patterns may be seen in the findings and recommendations in the

From the Department of Cardiothoracic Surgery, University of Texas Health Science Center San Antonio, San Antonio, Tex.

Disclosures: The authors reported no conflicts of interest.

The Journal policy requires editors and reviewers to disclose conflicts of interest and to decline handling or reviewing manuscripts for which they may have a conflict of interest. The editors and reviewers of this article have no conflicts of interest.

Received for publication March 4, 2021; revisions received March 4, 2021; accepted for publication March 4, 2021; available ahead of print March 8, 2021.

Address for reprints: Dawn S. Hui, MD, Department of Cardiothoracic Surgery, University of Texas Health Science Center San Antonio, 7703 Floyd Curl Dr, Suite

211L, San Antonio, TX (E-mail: huid@uthscsa.edu).

J Thorac Cardiovasc Surg 2023;165:567-8

$0022-5223 / \$ 36.00$

Copyright (C) 2021 by The American Association for Thoracic Surgery

https://doi.org/10.1016/j.jtcvs.2021.03.011

\section{Check for updates}

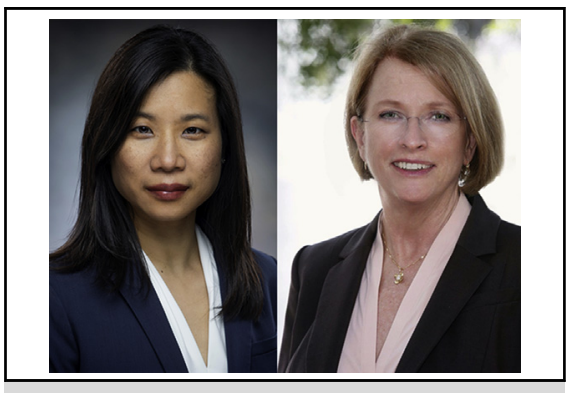

Dawn S. Hui, MD, and Andrea J. Carpenter, MD

CENTRAL MESSAGE

The findings of a study on aortic

root operation outcomes may

reflect the influence of previous

literature on practice patterns;

application should consider the

age of the patient and implica-

tions for future interventions.

previous literature, which are echoed by the findings of Yerokun and colleagues: a higher reoperation rate with VSRR and worse survival and stroke with mechanical Bentall. ${ }^{2,3}$

Some aspects of these decision pathways remain speculative, however. The mean follow-up of this study was only 5.0 years. Just as modes of failure vary, so too does the timing. Should we also consider the durability reoperation in our calculus? Within the midterm range, the higher reoperation rate of VSRR may prompt reticence to use this approach, but the jury is still out on how ViV TAVR compares to redo root operation for VSRR or stentless Bentall. Technical insights into bioprosthetic valve fracture have 